\title{
LA IGUALDAD ANTE LA LEY EN LA DOCTRINA DEL TJUE*
}

The equality before the law in the doctrine of the CJEU

\author{
José Manuel Martínez Sierra \\ Profesor de Derecho Constitucional \\ Universidad Complutense de Madrid \\ Jean Monnet ad personam Chair in EU Law and Government \\ Harvard University \\ jose_martinez@harvard.edu

\section{Covadonga Ferrer Martín de Vidales} \\ Profesora de Derecho Constitucional \\ Universidad Complutense de Madrid \\ cferrerm@ucm.es \\ doi: http://dx.doi.org/10.18543/ed-65(2)-2017pp211-245
}

Recibido: 10.02.2017

Aceptado: 28.11.2017

\section{Resumen}

El principio de igualdad ante la ley es un principio general del Derecho de la Unión Europea que, como el propio Tribunal de Justicia de la Unión Europea ha reconocido, se encuentra consagrado en todas las constituciones europeas. Constituye un principio fundamental del Derecho de la Unión y se encuentra asimismo

* Cómo citar / Citation 'Chicago-Deusto' (Autor-fecha / Author-date / Lista de referencias / Reference list entries): Martínez Sierra, José Manuel, y Covadonga Ferrer Martín de Vidales. 2017. «La igualdad ante la ley en la doctrina del TJUE». Estudios de Deusto 65, n. ${ }^{\circ}$ 2: 00-00. doi: http://dx.doi.org/10.18543/ed-65(2)-2017pp211-245. 
incorporado en la Carta de Derechos Fundamentales de la Unión Europea. El presente trabajo examina la evolución del reconocimiento del citado principio en la jurisprudencia del Tribunal. Además, analiza si la mencionada aprobación ha supuesto un cambio significativo en la predicha jurisprudencia. De ahí concluimos que la Carta de Derechos Fundamentales no ha mejorado el reconocimiento del Principio de Igualdad en el Derecho de la Unión Europea.

\section{Palabras clave}

Igualdad ante la ley, Carta de Derechos Fundamentales de la Unión Europea, jurisprudencia del Tribunal de Justicia de la Unión Europea.

\section{Abstract}

Equality before the law is a general principle of European Union Law which, as the Court of Justice of the European Union has recognized, is enshrined in all Member States constitutions. It constitutes a European Union Law fundamental principle and it is also incorporated in the Charter of Fundamental Rights of the European Union. This paper examines the equality principle evolution in the European Court case-law. Furthermore, it analyzes if the mentioned approval has implied a significant improvement in the mentioned jurisprudence. From there we conclude that the Charter of Fundamental Rights has not improved the Equality Principle recognition in the European Union Law.

\section{Keywords}

Equality before the law, Charter of Fundamental Rights of the European Union, case-law of the Court of Justice of the European Union. 
Sumario: 1. Introducción. 2. El artículo 20 de la Carta de DeRechos Fundamentales de LA Unión EuROPEA EN CONTEXTO. 3. LA DOCTRINA DEL TJUE SOBRE EL PRINCIPIO DE IGUALDAD ANTE LA LEY. 3.1 La jurisprudencia del TJUE anterior a la CDF. 3.2 La jurisprudencia posterior a la aprobación de la CDF. 4. CONCLUSIÓN.

\section{INTRODUCCIÓN}

La igualdad ante la ley es un derecho reconocido en la mayoría de las Constituciones contemporáneas ${ }^{1}$ y textos internacionales de protección de los Derechos fundamentales ${ }^{2}$. Su reconocimiento genérico supone el reconocimiento del derecho a la igualdad en la ley, a la igualdad en la aplicación de la ley, implicando la prohibición a toda discriminación ${ }^{3}$. Ahora bien, por otro lado, debe también recordarse que no cualquier trato desigual es discriminatorio, sino sólo el que no está basado en causas objetivas y razonables, es decir, el que es arbitrario ${ }^{4}$. La igualdad, por tanto, en ocasiones puede requerir que se traten de manera diferente ciertas situaciones, especialmente cuando los sujetos no se encuentran en situaciones comparables ${ }^{5}$.

En el ámbito comunitario, los Tratados fundacionales no contenían ninguna mención general a la protección de los derechos fundamentales en las Comunidades Europeas. Dicha mención no se encuentra hasta el Preámbulo del Acta Única Europea ${ }^{6}$, no siendo hasta el Tratado de la Unión

${ }^{1}$ Por ejemplo, el art. 14 de la Constitución Española, que establece la igualdad de todos los españoles ante la ley y prohíbe toda clase de discriminación por razones o condiciones personales o sociales. Constitución Española, $\mathrm{BOE} \mathrm{n}^{\circ} 311$, de 29 de diciembre de 1978.

${ }^{2}$ Como por ejemplo la Declaración Universal de Derechos Humanos de 1948, que proclama en su art. 7 la igualdad de todos ante la ley y el derecho a una igual protección de la misma.

3 Vid. A. E. Pérez Luño, Dimensiones de la igualdad (Dykinson, Madrid, 2007), 19.

${ }^{4}$ Vid. M. A. Aparicio Pérez, Manual de Derecho Constitucional (Atelier, Barcelona, 2009), 663-664.

5 Vid. S. Enchelmaier, «Equality rights, market economy, free competition and rights of equality», C. Ruiz de Miguel (coord..), Estudios sobre la Carta de los Derechos Fundamentales de la Unión Europea (Universidad de Santiago de Compostela, 2004), 56.

${ }_{6}$ Preámbulo AUE: «Decididos a promover conjuntamente la democracia, basándose en los derechos fundamentales reconocidos en las Constituciones y leyes de los Estados miembros, en el Convenio Europeo para la protección de los Derechos Fundamentales y las Libertades públicas y en la Carta Social Europea, en particular la libertad, la igualdad y la justicia social [...]». AUE, DO L 169, de 29 de junio de 1987. 
Europea, firmado en Maastricht en 1992, cuando se incorpora en el texto del Tratado algunas el compromiso de la Unión con el respecto a los derechos fundamentales ${ }^{7}$. Tratado, no obstante, que no venía sino a recoger la protección dada por el TJUE por vía pretoriana. Ámsterdam y Niza confirmaron ese régimen de protección de los derechos fundamentales en la Unión Europea, proceso que culmina con la última reforma llevada a cabo por el Tratado de Lisboa, reconociendo actualmente el art. 2 del TUE que «la Unión se fundamenta en los valores de respeto de la dignidad humana, libertad, democracia, igualdad, Estado de Derecho y respeto de los derechos humanos, incluidos los derechos de las personas pertenecientes a minorías», incluyéndose por primera vez una mención expresa al principio e igualdad ${ }^{8}$.

Por otra parte, la Carta de Derechos Fundamentales ${ }^{9}$ (en adelante, CDF), que como recoge el art. 6.1 del TUE tiene el mismo valor jurídico que los Tratados, recoge la igualdad ante la ley en su artículo 20, respecto del cual las Explicaciones a la Carta señalan que «corresponde a un principio general de Derecho que figura inscrito en todas las constituciones europeas y que el Tribunal de Justicia consideró un principio fundamental del Derecho Comunitario» ${ }^{10}$; explicaciones en las que se citan tres sentencias del TJUE

7 Así, en el artículo F apartado 2 de dicho Tratado, se establecía que «La Unión respetará los derechos fundamentales tal y como se garantizan en el Convenio Europeo para la protección de los Derechos Humanos y de las libertades fundamentales, firmado en Roma el 4 de noviembre de 1950, y tal y como resultan de las tradiciones constitucionales comunes a los Estados miembros, como principios generales del Derecho comunitario». TUE 1992, DO C 191, de 29 de julio de 1992.

${ }^{8}$ Se modifica ligeramente la anterior redacción del art. 6.1 TUE: «La Unión se basa en los principios de libertad, democracia, respeto de los derechos humanos y de las libertades fundamentales y el Estado de Derecho, principios que son comunes a los Estados miembros.». Vid. Versión consolidada del TUE de 2006, DO C 321E, de 29 de diciembre de 2006. Para una visión de la evolución de la protección de los derechos fundamentales en el ámbito de la Unión, vid. J. M. Beneyto Pérez, (Dir.), Tratado de derecho y políticas de la Unión Europea. Tomo II. Derechos fundamentales (Aranzadi-Thomson Reuters, Cizur Menor), 2009.

9 Sobre la CDF, pueden consultarse los siguientes comentarios: S. Peers; T. Hervey; J. Kenner; A. Ward, The EU Charter of Fundamental Rights: A Commentary (Hart Publishing, Oxford, 2014); A. Mangas Martín (Dir.), Carta de los Derechos Fundamentales de la Unión Europea. Comentario artículo por artículo (Fundación BBVA, Bilbao, 2008).

${ }_{10}$ Explicaciones sobre la Carta de los Derechos Fundamentales, Diario Oficial de la Unión Europea C 303, de 14 de diciembre de 2007. Para una visión crítica de las Explicaciones a la Carta, vid. J. M. Martinez Sierra, «La Carta de los Derechos Fundamentales: dos pasos atrás y uno al lado», AA.VV.; La Constitución Destituyente de Europa. Razones para otro debate constitucional (Ed. Catarata, Madrid, 2005), 85-118. 
como referencia de la doctrina sentada por el Tribunal con respecto al señalado principio.

Junto a dicha ausencia, el establecimiento de las cuatro libertades básicas -libre circulación de mercancías, personas, servicios y capitales-, y el spill over que las mismas provocaron -mercado común, mercado único, etc.introdujeron la igualdad en el derecho comunitario de una forma heterodoxa desde la perspectiva constitucional. Allí, el papel del Tribunal de Luxemburgo fue crucial para elevar el reconocimento de lo que podíamos llamar la «igualdad para el mercado» a partir de reconocimientos específicos en los tratados fundacionales: los actuales artículos 119 y 120 del TFUE (antiguos artículos 4 y $98 \mathrm{TCE}$ ), que prevén que los Estados miembros y la Unión Europea actuarán, en el ámbito de la política económica y monetaria, respetando el principio de una economía abierta y de libre competencia; el artículo 26.2 (artículo 14.2 TCE), que dispone que el mercado interior implicará un espacio sin fronteras interiores en el que la libre circulación de mercancías, personas, servicios y capitales estará garantizada; los artículos 101 a 106 TFUE (artículos 81 a 86 TCE), que recogen las normas aplicables a la competencia, y 107 a 109 TFUE (artículos 87 a 89 TCE), en materia de ayudas de estados, esenciales para el buen funcionamiento del mercado interior y la realización del mencionado principio. El mercado interior garantiza que todas las transacciones se realicen de forma libre en todos los Estados miembros, prohibiéndose todo tipo de discriminación, como demuestra la jurisprudencia del TJUE ${ }^{11}$.

El presente estudio tiene por objeto examinar la evolución que el reconocimiento del principio de igualdad ha sufrido en la jurisprudencia del TJUE $\mathrm{y}$, en concreto, si la aprobación de la CDF ha supuesto un cambio en la citada jurisprudencia, aumentando la garantía del principio de igualdad, o si por el contrario se mantienen las líneas principales ya apuntadas por el TJUE con anterioridad a su aprobación.

Para conseguir dicho fin, examinaremos, en primer lugar, el contenido del citado artículo 20, su contexto interpretativo y las explicaciones de la CDF. En un segundo momento pasaremos a realizar un análisis cronológico de la jurisprudencia del TJUE: de un lado, abordando la jurisprudencia anterior a la aprobación de la CDF -y prestando parada obligada en las sentencias que las Explicaciones de la Carta toman como referencia de la doctrina del Tribunal en relación con el principio examinado-; de otro, la jurisprudencia posterior adoptada tras la aprobación de la Carta. Todo ello con el objeto de comprobar si, como se ha señalado, se mantienen las líneas apuntadas en la jurisprudencia previa.

${ }^{11}$ Para más información, vid. S. Enchelmaier, op. cit., 76 y ss. 


\section{EL ARTÍCULO 20 DE LA CARTA DE DERECHOS FUNDAMENTALES DE LA UNIÓN EUROPEA EN CONTEXTO}

El Título III de la CDF contiene, bajo el genérico título de igualdad, dos tipos de preceptos. De un lado, conformado el núcleo duro del título, las cláusulas horizontales que conforman las garantías genéricas de la igualdad, tanto en su dimensión positiva como negativa, respectivamente: Artículo 20: igualdad ante la ley; y Artículo 21: No discriminación; Artículo 23: Igualdad entre hombres y mujeres. Por otro lado, encontramos una serie de preceptos verticales, centrados en formas específicas de discriminación y desigualdad, de diversa índole: hombre, mujer, menores, personas mayores, discapacitados. Entre estos segundos podemos encuadrar, aunque adelantando su idiosincrásica naturaleza jurídica, el compromiso de la Unión con el respeto a la diversidad cultural, religiosa y lingüística.

Esta diversidad y su peculiar estructuración en el Título responde a la preocupación de los redactores de la CDF por ser originales, y a la necesidad de abordar el ámbito recogiendo la peculiaridad del acervo comunitario. Independientemente de las causas de tal variedad, la misma, hace necesario una reflexión previa de tipo metodológico sobre las dimensiones que la igualdad tiene en el contexto europeo.

La opción más sencilla a la hora de configurar el contorno del principio de igualdad, desde el punto de vista de la técnica legal, es hacerlo en dialéctica con la otra cara de la moneda, el principio de no discriminación. Hacerlo delimitando las fronteras de la discriminación entre sujetos definimos en negativo el contenido diáfano de la igualdad en sentido estricto. Cuando el constituyente impide que el poder constituido utilice en el proceso legislativo elementos objeto de introducir disparidad de trato -como la raza, el sexo o la edad-, el legislador se ve abocado a legislar en abstracto, haciendo sujeto pasivo de la norma a la persona sin adjetivación.

Pero, como es sabido, el derecho, afortunadamente, no es un compartimiento estanco. A parte de estar dotado de los requisitos de legitimidad y legalidad requeridos, es útil a la sociedad a la que sirve. La adaptación del principio de igualdad le demanda huir de la rigidez del paradigma teórico expuesto e introducirse en sendas de flexibilidad. Sin duda, la parte crucial de la relación dialéctica igualdad-discriminación, depende de las justificaciones de discriminación permitidas en el ordenamiento. No hay, como puede deducirse de la interrelación derecho-constitución-sociedad, un elenco cerrado continente de las justificaciones de discriminación en el ordenamiento europeo. De ahí que, en esta exégesis, sea conveniente atenerse a los antecedentes jurisprudenciales.

Siguiendo con la contextualización del precepto, a parte de la opción derivada de la dialéctica con el principio de no discriminación, se puede 
incorporar la interpretación sistemática del principio. Se puede por ejemplo buscar referencias cruzadas con la multiplicidad de preceptos que, frente a la histórica especificidad sectorial del Derecho Originario, ofrecen hoy, al menos en principio, un contraste hermenéutico amplio del predicho cariz. De un lado, con los surgidos del giro constitucional del mismo, vuelco que pretende huir del iusinternacionalismo para dirigirse con menos ambages hacia el constitucionalismo y el Estado de derecho. En este punto encontramos, en el Preámbulo del TUE, la clásica mención a «los valores universales de los derechos inviolables e inalienables de la persona humana, la democracia, la igualdad, la libertad y el Estado de Derecho»; y posteriormente, en el Artículo 2: Valores de la Unión, el refrendo al preludio: «La Unión se fundamenta en los valores de respeto de la dignidad humana, libertad, democracia, igualdad, Estado de Derecho y respeto de los derechos humanos, incluidos los derechos de las personas pertenecientes a minorías».

Por otra parte, encontramos la formulación, reformulación o reproducción del acervo clásico, aquel que está conectado a las libertades básicas, heredero de la persona reducida a su condición de trabajador y que se intenta unir al novedoso en términos histórico-comunitarios, vinculado al ciudadano de la Unión. Asimismo, incluiríamos aquí el segundo párrafo de la clásica dimensión negativa del principio estudiado en el Artículo 3.3: Objetivos de la Unión, «La Unión combatirá la exclusión social y la discriminación y fomentará la justicia y la protección sociales, la igualdad entre mujeres y hombres, la solidaridad entre las generaciones y la protección de los derechos del niño». Incluso el artículo 2: Valores de la Unión, in fine, señala que «Estos valores son comunes a los Estados miembros en una sociedad caracterizada por el pluralismo, la no discriminación, la tolerancia, la justicia, la solidaridad y la igualdad entre mujeres y hombres».

La relación entre ambos grupos de preceptos, difícilmente puede plantearse en términos de jerarquía ortodoxa desde la perspectiva constitucional. Básicamente porque la vis atractiva de los primeros está cortocircuitada por las cláusulas horizontales y por la propia naturaleza jurídica y configuración de las libertades básicas del mercado común. Libertades que, no podemos olvidarlo, han sido encumbradas por la jurisprudencia del TJUE por encima de los Derechos fundamentales clásicos. Por ello, sin entrar en la visión global de la Carta y del modelo -que corresponde al estudio del Título VII de la Carta-, no puede dejar de señalarse que el derecho comunitario es, desde su génesis, gregario del mercado común y no del Estado Social. Por eso, aquello que nos preocupa en estas líneas, la ubicación de los derechos fundamentales -en concreto el referido a la igualdad- en la Carta, presume que difícilmente pueda ser el de las constituciones continentales hijas del Estado Social, pues el núcleo duro del mercado único es forzosamente el primer y principal parámetro de aplicabilidad y justiciabilidad. 
Según esta lógica, el TJUE vendría impelido a continuar con su doctrina tradicional, de acuerdo con la cual, los estándares de protección más elevados no son necesariamente los reconocidos ni en los Estados miembros ni en el Convenio Europeo de Derechos Humanos (CEDH), lo son en la medida que permitan mantener el acervo comunitario, que se blinda respecto de interpretaciones extensivas de la CDF con su ubicación fuera y frente a los límites de la misma. Lo que se pretende es buscar parámetros de referencia del precepto estudiado, esto es, estar a la doctrina del TJUE. Tendremos que atender al refrendo de esta tesis en las conclusiones.

Por último, la contextualización adecuada del precepto, requiere atender a la concepción del mismo en el momento de redacción de la Carta, es decir, requiere ser estudiado desde la presunción iuris tamtum, que no iure et de iure, de que los redactores posicionaron el precepto en la media de contenido y alcance de su momento histórico. En el momento histórico de redacción del precepto estudiado, el de la mayoría social y académica, frente al de la mayoría existente en la redacción de las principales constituciones de los Estados miembros, entendía ya que la igualdad no es solamente un camino inoculado en la norma suprema, la igualdad es un fin, es decir, el horizonte del legislador que nunca estará lo suficientemente presente. No se trata únicamente de garantizar la igualdad de partida entre los sujetos pasivos de la norma, se trata de que la aplicación del principio culmine en igualdad real, en tiempo real, que no en futuro. Este argumento parte de la base de que, hombres y mujeres, discapacitados y plenamente capaces, etc., no son iguales. Por ello, en las sociedades modernas se considera que, en ocasiones, no basta con diseñar un esquema normativo que garantice la igualdad, sino que sea necesario introducir ajustes de iure que posibiliten la igualdad de facto. Paradigmático ejemplo de la insuficiencia de la igualdad abstracta, dentro y fuera de la Unión, es el acceso de la mujer al trabajo y el desarrollo de la carrera profesional. Sus condicionantes -maternidad, responsabilidades familiares no compartidas, entre otras- demandan más que la igualdad formal.

Las limitaciones del modelo basado en la no discriminación, han excitado la denominada igualdad sustantiva, que se caracteriza por abandonar la neutralidad aséptica a la que puede llegar aquel modelo. Como ha destacado autorizada doctrina, la igualdad sustantiva encierra una pluralidad de acepciones $^{12}$. Ciertamente, la que busca la igualdad de trato ab inito, dejando a los sujetos la consecución de la igualdad real. Se trata aquí de identificar los obstáculos con los que cuentan determinados grupos sociales para articular mecanismos que los eliminen o, subsidiariamente, con carácter temporal o estructural -dependiendo de las previsiones de corrección-, establecer

${ }^{12}$ Seguimos aquí a S. Fredman, Discrimination Law (Claredon Press, Oxford, 2001), 14 y ss. 
mecanismos compensatorios. Junto con la igualdad de trato ab inito, nos encontraríamos con una corrección más intensa, la dirigida a conseguir la igualdad de resultados. Conocido mecanismo sería la utilización de la cuota para forzar la presencia de un sector marginado de un ámbito concreto: social, étnico, etc.

En tercer lugar, podemos hablar, tanto dentro como fuera de la Unión, de la igualdad como diversidad. Desde 1999 y debido a la penúltima reforma del Derecho originario europeo, la agenda de la igualdad en la UE se amplio considerablemente debido a la inclusión de la base jurídica que hacía competente a la UE para combatir la discriminación por razón sexo, origen racial o étnico, orientación sexual, religión, etc. Esta circunstancia incrementó en la UE un problema ya común en los ordenamientos más desarrollados y progresistas: la necesidad de articular el respeto a la diversidad. Si reconocemos la posibilidad de enseñanza privada de una determinada confesión y el principio de igualdad a la función docente sin discriminación por razón de la orientación sexual: ¿puede un colegio católico negarse a contratar a un profesor homosexual? Como se ha señalado, ${ }^{13}$ acomodar igualdad y diversidad, demanda la inoculación del principio de igualdad en todos los ámbitos competenciales. Dicha realidad tiende a un proceso ostensiblemente más flexible que el desarrollado al amparo de la igualdad sustantiva, pues demanda un objetivo común de igualdad para toda forma de discriminación.

De lo deducido sobre esta última contextualización, tendremos que corroborar o no la presunción iuris tamtum, sobre si el precepto se posicionó en la media de contenido y alcance del momento histórico en el que fue redactado e introducido en el derecho de la UE. En caso de que el contenido haya alcanzado ese claro avance, la Carta habrá incrementado el reconocimiento disfrutado por los ciudadanos de muchos Estados miembros -dado que la inmensa mayoría de ellos no había realizado reforma constitucional avanzada- y, a la sazón, habrá dado al TJUE una palanca de avance en el reconocimiento de los derechos fundamentales en toda la Unión. En caso de no ser así, nuestras conclusiones dependerán exclusivamente de la actitud que haya tomado el TJUE.

\section{LA DOCTRINA DEL TJUE SOBRE EL PRINCIPIO DE IGUALDAD ANTE LA LEY}

Como se ha adelantado en la introducción de este estudio, las explicaciones a la CDF certificaron la consolidada existencia del reconocimiento del

${ }^{13}$ M. Bell, «The right to equality and Non-discrimination», T. Hervey; J. Kenner (Ed.), Economic and Social Rights Under the EU Charter of Fundamental Rights (Hart Publishing, Oxford, 2003), 96-97. 
principio genérico de igualdad en la doctrina del TJUE, tanto en la forma parafraseando la formulación del TJUE- como en el fondo -no incluyendo ningún elemento añadido a esa formulación-. Sirva esto como primer indicio de que la CDF se daba por satisfecha con el contenido y la garantía formulada en la doctrina del tribunal de Luxemburgo anterior a la propia Carta. Y sirva como indicio del proceso inverso el hecho de que el propio TJUE citó la «nueva» recepción de los derechos fundamentales en el Derecho de la Unión en la CDF en sus sentencias con carácter previo incluso a que esta entrara en vigor, dando así a entender que la Carta recogía lo que ya recogía su doctrina, sin indicar la futurible entrada en vigor fuera a provocar cambio alguno en su doctrina, o lo que es lo mismo, que nada iba a cambiar significativamente en este ámbito concreto en el derecho europeo con la entrada en vigor de la CDF.

En el ámbito que nos ocupa, como en tantas ocasiones, la fundamentalidad de los derechos y principios del derecho europeo, son inferidos con desigual robustez. No podemos entrar aquí en la dialéctica TJUE-tribunales constitucionales de los Estados miembros, que en buena medida desencadenó la necesidad y la celeridad de explicitar la fundamentalidad de ciertos principios y derechos en el ordenamiento comunitario y que hemos estudiado profusamente ${ }^{14}$. Dicha realidad no solamente implicó que la incorporación se hiciera por la vía de los principios generales del derecho -a lo que coadyuvaron otros factores como la imposibilidad, por ausencia de voluntad política, de reformar el derecho originario-, sino también y más trascendentemente, para lo que aquí nos mueve, que se hiciera desde supuestos de hecho sumidos en la casuística sectorial que no hacían natural el desarrollo de principios generales del ordenamiento, provocándose una desconexión y ausencia de formulación global.

Dicha realidad, mostrada de forma inmediata, determina la aplicación de un método basado en el estudio consecutivo de los distintos asuntos en los que el principio se reflejó. Realizada la batida, atendiendo a los distintos supuestos de hecho, se procedería a extraer-o bien constatar la imposibilidad de hacerlo- las enseñanzas interpretativas. Comencemos.

Según las explicaciones de la CDF, su artículo 20 corresponde a un Principio General de Derecho europeo que figura en todas las constituciones europeas. El Tribunal de Justicia, teniendo en cuenta esta realidad, y en el marco de una tensión creciente sobre la afectación generada por la UE en el marco de derechos de los ciudadanos de la $\mathrm{UE}^{15}$, pasó a considerarlo un principio fundamental del Derecho comunitario (sentencia de 13 de noviembre de 1984, Racke, asunto 283/83, Rec. 1984, p. 3791; sentencia de 17 de abril de 1997, C

${ }^{14}$ Sobre esta construcción in extenso, J. M. Martínez Sierra, La recepción constitucional del derecho comunitario (Tirant lo Blanch, Valencia, 2007).

15 Ibidem. 
15/95, EARL, Rec. 1997, p. I-1961, y sentencia de 13 de abril de 2000, C 292/97, Karlsson, Rec. 2737). Se hace pues obligado, estar a estas sentencias, aunque, debido precisamente a su ausencia de riqueza hermenéutica, no serán las únicas analizadas. De hecho, prestaremos especial atención a aquellas que han sido dictadas con posterioridad a la entrada en vigor de la CDF.

La formulación del principio de igualdad en el Derecho europeo, tal y como ha sido formulado y sostenido en la doctrina del TJUE sería la siguiente: «el principio general de igualdad, exige que no se traten de manera diferente situaciones comparables y que no se traten de manera idéntica situaciones diferentes, a no ser que dicho trato esté objetivamente justificado» ${ }^{16}$. Principio que el TJUE ha confirmado que se encuentra consagrado por los artículos 20 y 21 de la Carta ${ }^{17}$.

Una mera lectura de la explicitación del principio permite afirmar, sin necesidad de realizar un mayor despliegue teórico sobre los cánones hermenéuticos ortodoxos, que la interpretación literal de la formulación del principio por parte del TJUE deja dos cuestiones completamente abiertas Por un lado, la referida a la determinación de lo que constituye una situación comparable, lo cual depende en gran medida de los hechos de cada caso y de una valoración subjetiva por parte del juzgador ${ }^{18}$. Por otro, la relacionada con la delimitación del concepto de «trato desigual objetivamente justificado». Dicha realidad, como señala Bell, es consecuencia del énfasis de la jurisprudencia del TJUE en un concepto de igualdad formal y similitud en el trato ${ }^{19}$. $\mathrm{Y}$ es lo que ha determinado, en parte, como señala $\mathrm{O}^{\prime}$ Cinneide, el desarrollo de la igualdad desde su dimensión negativa, es decir, del principio de no discriminación ${ }^{20}$.

${ }^{16}$ SSTJUE de 21 de julio de 2011, Károly Nagy contra Mezőgazdasági és Vidékfejlesztési Hivatal, C-21/10, Rec. 2011 p. I-6769, ap. 47; de 12 de mayo de 2011, Gran Ducado de Luxemburgo c. Parlamento y Consejo, C-176/09, Rec. 2011 p. I-3727, ap. 31; de 14 de septiembre de 2010, Akzo Nobel Chemicals Ltd v. Comisión, C-550/07 P, Rec. 2010 p. I-08301, ap. 55; de 16 de diciembre de 2008, Arcelor Atlantique y Lorraine y otros, C-127/07, Rec. p. I-9895, ap. 23; de 3 de mayo de 2007, Advocaten voor de Wereld, C-303/05, Rec. 2007 p. I-03633, ap. 56; y de 10 de enero de 2006, IATA y ELFAA, C-344/04, Rec. p. I-403, ap. 95.

17 SSTJUE de 22 de mayo de 2014, Wolfgang Glatzel contra Freistaat Bayern, C-356/12, Rec. Jurisprudencia electrónica, ap. 43; de 21 de julio de 2011, Károly Nagy contra Mezőgazdasági és Vidékfejlesztési Hivatal, C-21/10, Rec. 2011 p. I-06769, ap. 47; de 14 de septiembre de 2010, Akzo Nobel Chemicals Ltd v. Comisión, C-550/07 P, Rec. 2010 p. I-08301, ap. 54.

18 Vid. M. Bell, «Article 20», S. Peers; T. Hervey; J. Kenner; A. Ward, (eds.), The EU Charter of Fundamental Rights: A Commentary (Hart Publishing, Oxford, 2014), 571.

${ }_{19}$ Ibid.p. 571.

${ }^{20} \mathrm{Vid}$. C. O'Cinneide, «The principle of equality and non-discrimination within the framework of the EU Charter of Fundamental Rights and its potential application to social 
Examinaremos a continuación la jurisprudencia del TJUE anterior y posterior a la aprobación de la Carta, con el objeto de comprobar si la misma ha implicado un salto cualitativo en el reconocimiento de la igualdad ante la ley y mejora la garantía de la misma, o si por el contrario se mantiene una interpretación limitativa del mismo.

\subsection{La jurisprudencia del TJUE anterior a la CDF.}

Desde su jurisprudencia más temprana, el TJUE ha destacado que el principio de igualdad es un principio que forma parte de los principios fundamentales del ordenamiento europeo y que en virtud del mismo las situaciones comparables no deben recibir un trato diferente, a menos que éste esté objetivamente justificado ${ }^{21}$. Una primera cuestión, por tanto, es determinar si dos situaciones pueden considerarse como comparables para, si es así, pasar en segundo término a examinar si la diferencia de trato está objetivamente justificada. A este respecto, el TJUE señala que han de tenerse en cuenta el conjunto de elementos que caracterizan dichas situaciones comparables, elementos que deben apreciarse a la luz del objeto y la finalidad del acto europeo que establece la distinción de que se trata, así como de los principios y objetivos del ámbito al que pertenece el acto en cuestión ${ }^{22}$. Remite de esta manera el tribunal al análisis del acto europeo y del ámbito al que pertenece, lo que demanda el examen de los supuestos de hecho concretos de cada caso.

Ahora bien, en el presente apartado centraremos nuestro análisis en las tres sentencias que las Explicaciones a la Carta citan como sentencias de referencia en relación al mencionado principio, ya que las mismas recogen la doctrina sentada por el TJUE con respecto al mismo.

El primero de los tres casos que se citan en las citadas Explicaciones es el asunto Racke ${ }^{23}$; asunto que, como el resto de la doctrina del TJUE en este ámbito, no deja de ser una resolución del caso concreto que recoge el principio sin afrontar de una manera general su contenido y aplicación en el ámbito Europeo, ni con referencia a la normativa internacional ni a Constituciones europeas. El asunto traía causa de una cuestión prejudicial del Finanzgericht

and solidarity rights», G. Palmisano (ed.), Making the Charter of Fundamental Rights a living instrument (Brill Nihjof, Leiden/Boston, 2015), 203.

${ }_{21}$ Vid, por ejemplo. SSTJUE de 25 de noviembre de 1986, Klensch y otros, asuntos acumulados 201/85 y 202/85, Rec. 1986 p. 3477, ap. 9; de 5 de octubre de 1994, Alemania c. Consejo, C-280/93, Rec. 1994 p. I-04973, ap. 64.

22 SSTJUE de 5 de octubre de 1994, Alemania/Consejo, C-280/93, Rec. 1994 p. I-4973, ap. 74; de 10 de marzo de 1998, T. Port, C-364/95 y C-365/95, Rec. 1998 p. I-1023, ap 83. Como se examinará en el siguiente apartado, esta jurisprudencia se mantiene tras la CDF.

${ }^{23}$ STJUE de13 de noviembre de 1984, Racke, 283/83, Rec. 1984, p. 3791. 
Rheinland-Pfalz, que instó al TJUE a pronunciarse sobre la compatibilidad del Reglamento número 1167/76 de 17 de mayo de 1976, con el apartado tercero del artículo 40 TCEE, pues excluía los vinos de Tokay -en el contexto de las comisiones de cambio- de un régimen especifico de la Tarifa Aduanera Común y le mantenía en el régimen general frente a lo estipulado para productos similares.

El TJUE encaró la resolución del caso en dos fases. En primer lugar definiendo el principio general de igualdad en su dimensión negativa: «la discriminación no solamente puede consistir en la aplicación de reglas diferentes a situaciones comparables o bien en que se apliquen reglas idénticas a situaciones diferentes» ${ }^{24}$. En segundo lugar, aplicando ese principio general al supuesto de hecho, afirmó que se trataba de ver si la aplicación de un régimen de tarifas diferentes estaba justificado por situaciones distintas. Finalmente, el TJUE concluyó que el régimen de tarifas diferentes estaba justificado por quedar los productos objetos del asunto (vinos de Tokay) sometidos a un régimen distinto al de los vinos utilizados por los demandantes como referencia en el estudio de la discriminación ${ }^{25}$.

Ocho años después del fallo estudiado, en un supuesto de hecho similar -relativo a la imposición una tasa adicional sobre la leche, el asunto Wuidart ${ }^{26}$-, el TJUE mantuvo el test y la solución dada en el asunto Racke. En concreto, consideró que la distinta naturaleza en lo relativo a la denominación de origen y otros aspectos colaterales, justificaban el dispar tratamiento que le había dispensado el legislador.

El segundo asunto reconocido como cardinal en relación con el principio tratado por la Convención redactora de la Carta, es el asunto EARL de

24 «[...] il y a lieu de vérifier si la situation du vin de tokay est comparable a celle des vins pour lesquels les droits de douane fixes en écus ont été convertis en monnaie nationale au taux représentatif, e étant donne qu'une discrimination ne peut consister, d' après la jurisprudence constante de la cour, que dans l'application de règles différentes a des situations comparables ou bien dans l'application de la même règle a des situations différentes. En 1 ' espèce, il s ' agit d ' établir si 1 ' application d ' un taux différent de conversion des droits de douane est justifiée par la diversité des situations», Ibid., ap. 79.

25 «10 Aucun problème de ce genre ne se posait par contre pour les vins exclus de l'application de la taxe compensatoire, de sorte qu'aucune comparaison entre les deux situations n'apparaît justifiée. [...] Il ressort des considérations qui précèdent que l'application de règles différentes aux deux situations susindiquees n'entraîne pas de violation du principe de non-discrimination. [...] Par conséquent, il convient de répondre au premier volet de la question en ce sens que l'examen du dossier ne fait apparaître aucun élément permettant d ' affirmer que le règlement n 1167/76 est contraire a l' article 40, paragraphe 3, alinéa 2 , du traite», Ibid., app. 10, 11, 12.

${ }^{26}$ SSTJUE du 21 février 1990, Gustave Wuidart e.a. c. Laiterie coopérative eupenoise société coopérative, e.a., Affaires jointes C-267/88 à C-285/88, Rec. 1990 page I-435. 
Kerlast, conocido en la jerga comunitaria como $E A R L^{27}$. El asunto tiene su génesis en una petición de decisión prejudicial del Tribunal de grande instance de Morlaix. Mediante su tercera cuestión, el órgano jurisdiccional predicho pidió fundamentalmente que se dilucidara por parte del TJUE si el principio de igualdad contenido en el párrafo segundo del apartado 3 del artículo 40 del Tratado se oponía a que un Estado miembro autorizase, para ejercer una actividad lechera, la utilización de determinadas formas societarias previstas por el Derecho nacional, como el «groupement agricole d'exploitation en commun», mientras que prohibía el uso de otras formas societarias como la «société en participation»; entendiendo que por la similitud de la naturaleza jurídica de las sociedades cabía la duda sobre la vulneración del principio de igualdad en su dimensión negativa. El TJUE, siguiendo la línea general definida, denegó la existencia de discriminación de nuevo entendiendo que no se trataba de situaciones comparables.

Entrando en la rationale de la sentencia, el TJUE cita ab initio la formulación clásica del principio con cita expresa del asunto España c. Consejo: «la prohibición de discriminación, no es sino la expresión específica del principio general de igualdad que forma parte de los principios fundamentales del Derecho comunitario y que exige que no se traten de manera diferente situaciones comparables y que no se traten de manera idéntica situaciones diferentes, a no ser que dicho trato esté objetivamente justificado ${ }^{28}$. En segundo lugar, reconoce que la legislación nacional «reservan un trato diferente a los productores agrupados en una «société en participation» y a los agrupados en un «groupement agricole d'exploitation en commun» parcial lechero, en la medida en que sólo se prohíbe a los primeros el ejercicio de una actividad lechera $\rangle^{29}$. En tercer lugar, explicita la razón de ser por la cual este trato disímil no vulnera el principio general. En este caso, resulta ser la distinta naturaleza jurídica de las sociedades implicadas en el recurso del que traía causa la cuestión prejudicial: «Esta diferencia de trato no puede constituir una violación del principio de no discriminación. En efecto, las situaciones a las que hacen referencia estas dos formas societarias no son comparables, $[\ldots]$ en el «groupement agricole d'exploitation en commun» parcial lechero, los asociados participan personal y efectivamente en el trabajo de producción lechera, mientras que, en la "société en participation», el trabajo de producción puede encomendarse a un solo asociado. En consecuencia, esta última figura societaria puede favorecer formas de producción que no se ajustan al Reglamento comunitario de que se trata».. ${ }^{30}$

27 STJUE de 17 de abril de 1997, EARL de Kerlast c. Union régionale de coopératives agricoles (Unicopa) y Coopérative du Trieux, C-15/95, Rec. 1997, p. I- 01961.

28 Ibid., ap. 25.

${ }^{29}$ Ibid., ap. 37.

30 STJUE C-15/95, ap. 38. 
Por último, el tercero de los asuntos citados en las Explicaciones a la Carta, como piedra angular de la configuración del principio de igualdad ante la ley como un principio fundamental del Derecho de la Unión por el TJUE, es el asunto Karlsson ${ }^{31}$. Si de muestra vale un botón, sirva como ejemplo del papel medular del asunto en la configuración del principio de igualdad ante la ley como un principio fundamental del Derecho comunitario el hecho de que, no habiéndose llegado a publicar la sentencia cuando se redactaron las explicaciones de la Carta de Niza, se incluyó con la acotación que reflejaba tal hecho ${ }^{32}$. Una vez publicada, en las explicaciones vigentes, se ha eliminado tal acotación.

El asunto Karlsson trajo causa de una cuestión prejudicial promovida por el Regeringsrätten sueco, destinada a obtener, en los procedimientos promovidos ante dicho órgano jurisdiccional por Kjell Karlsson y otros, una decisión prejudicial sobre la interpretación del Reglamento (CEE) n. 3950/92 del Consejo, de 28 de diciembre de 1992, por el que se establece una tasa suplementaria en el sector de la leche y de los productos lácteos, de los artículos 5 del Tratado CE (artículo 10 CE) y 40, apartado 3, del Tratado CE (artículo 34 $\mathrm{CE}$, apartado 2, tras su modificación), y del principio de igualdad de trato.

Resumiendo el conflicto a quo, se trataba de dilucidar si el Reglamento n. 3950/92, el artículo 5 del Tratado y el principio de igualdad de trato -establecido en el artículo 40, apartado 3, del Tratado- se oponían a una normativa sobre asignación inicial de cuotas lecheras, aprobada por un Estado miembro que se adhirió a las Comunidades Europeas el 1 de enero de 1995. La misma determinaba las cuotas lecheras de los productores regulares sobre la base de las cantidades medias entregadas durante los años 1991 a 1993; aplicaba, para el cálculo de las cuotas asignadas a los nuevos productores y a los productores en crecimiento, a diferencia de los productores regulares y de los productores ecológicos, coeficientes de reducción que además eran diferentes; y únicamente concedía una cuota lechera a los productores que justificasen una producción ininterrumpida entre el 1 de marzo de 1994 y el 1 de enero de 1995.

Se estaba pues, ante un posible trato desigual que, aparte de lo siempre céntrico en la materia estudiada, su naturaleza, encontraba un matiz diferenciador, el de estar modulada por las modificaciones introducidas en el derecho derivado europeo, por una modificación del derecho originario. Así, el Reglamento CEE no 3950/92 del Consejo, de 28 de diciembre de 1992, por el que se establecía una tasa suplementaria en el sector de la leche y de los productos lácteos,

31 STJUE de 13 de abril de 2000, Karlsson, C-292/97, Rec. 2000, p. 2737.

32 Ver la explicación al art. II-20 en las explicaciones la Carta de Niza, Texto de las explicaciones relativas al texto completo de la Carta, en la versión que figura en el doc. CHARTE 4487/00 CONVENT 50, Bruselas, 11 de octubre de 2000, CHARTE 4473/00, CONVENT49. 
fue modificado por el Acta relativa a las condiciones de adhesión de la República de Austria, de la República de Finlandia y del Reino de Suecia, adaptando igualmente los Tratados en los que se basa la Unión Europea.

La discriminación alegada respondía a una doble naturaleza. La primera radicaba en la dispar elaboración del producto o el momento en el que iniciaron la producción por los distintos productores implicados (productores ecológicos, nuevos productores, productores en crecimiento y productores regulares). La segunda, en la eventual discriminación de los productores suecos respecto del resto de productores comunitarios por la normativa sueca: los demandantes en los procedimientos principales sostuvieron que las exigencias sobre protección medioambiental que todo productor sueco debía cumplir en virtud del artículo 5 del Reglamento sueco n. 1714 constituían una discriminación de estos productores respecto de los productores de los demás Estados miembros, por suponer una carga mayor que la establecida para sus competidores.

El TJUE, introduciéndose en la cuestión relativa a las fuentes del derecho para determinar la normativa aplicable, basa su sentencia en el inalterado principio de igualdad de trato, tal y como fue establecido específicamente, en el artículo 40, apartado 3, párrafo segundo, del Tratado CE (artículo $34 \mathrm{CE}$, apartado 2, párrafo segundo, tras su modificación).

La primera de las discriminaciones potenciales, la establecida entre los distintos productores de Suecia, fue igualmente rechazada por el TJCE pese a constatarse -en concreto en el trato dispensado a los nuevos productores y a los productores en crecimiento respecto de los productores regulares- que «El Gobierno sueco no ignora que los nuevos productores y los productores en crecimiento se ven desfavorecidos en relación con los productores regulares» ${ }^{33}$ y que igualmente «El Gobierno sueco también es consciente de que el otro método de cálculo propuesto [...] tampoco puede paliar este trato desigual $\rangle^{34}$.

La fundamentación del rechazo a las demandas de la parte actora se basó en que las discriminaciones factuales, que no legales, respondían al interés general perseguido por la Unión: "según jurisprudencia consolidada, pueden establecerse restricciones al ejercicio de estos derechos, en particular en el ámbito de una organización común de mercado, siempre que dichas restricciones respondan efectivamente a objetivos de interés general perseguidos por la Comunidad y no constituyan, teniendo en cuenta el objetivo perseguido, una intervención desmesurada e intolerable que afecte a la esencia misma de dichos derechos ${ }^{35}$. Conviene aquí recordar que entre la doctrina consolidada

\footnotetext{
33 STJUE C-292/97, ap. 42.

${ }^{34}$ Ibid., ap. 43.

35 Ibid., ap. 45.
} 
está el asunto Wachauf $^{\beta 6}$, donde el TJUE situó los objetivos del interés general, en relación con el principio de igualdad, como paradigma del carácter no absoluto de los derechos fundamentales en el Derecho europeo.

Estamos aquí ante una puerta abierta a la discrecionalidad y consecuentemente ante otro embate al principio de seguridad jurídica, el cual, como sabemos, también está consagrado en la Carta y, con unas potencialidades mayores que el de igualdad, por no estar sujeto como el aquí estudiado a un amplio desarrollo jurisprudencial. Los objetivos de interés general son un pozo sin fondo: pueden extraerse de los Tratados como normas inspiradoras del sistema; de las conclusiones de la presidencia del Consejo Europeo, que tiene como carga general definir dichos objetivos en el marco de su competencia de dar los impulsos generales a la Unión; ciertamente del diseño legislativo de la Comisión que sigue manteniendo el monopolio de la iniciativa legislativa; eventualmente podrían encontrarse en el Consejo de Asuntos Generales ahora que con el Tratado de Lisboa recobra importancia; también en el Parlamento, bien en sus resoluciones bien en su poder de excitación a la iniciativa legislativa de la Comisión.

Dentro de los objetivos de interés general, podemos encontrarnos también soluciones $a d$ hoc, o bien su concreción en un ámbito específico. Ejemplo de este segundo sería el objetivo de la integración de mercados, que se ha postulado como justificador del trato diferenciado ante situaciones parejas en los asuntos Alemania c. Consejo ${ }^{37}$ o Port $^{38}$.

36 «Die vom Gerichtshof anerkannten Grundrechte können jedoch keine uneingeschränkte Geltung beanspruchen, sondern sind im Zusammenhang mit ihrer gesellschaftlichen Funktion zu sehen . Daher kann die Ausübung dieser Rechte, insbesondere im Rahmen einer gemeinsamen Marktorganisation, Beschränkungen unterworfen werden, sofern diese tatsächlich dem Gemeinwohl dienenden Zielen der Gemeinschaft entsprechen und nicht einen im Hinblick auf den verfolgten Zweck unverhältnismässigen, nicht tragbaren Eingriff darstellen, der diese Rechte in ihrem Wesensgehalt antastet». STUE de 13 de julio de 1989, Wachauf, 5/88, Rec. p. 2609, ap. 18.

37 «No obstante, este trato diferenciado parece inherente al objetivo de una integración de mercados hasta entonces fragmentados, habida cuenta de la situación distinta en la que se hallaban las diferentes categorías de operadores económicos antes del establecimiento de la organización común de mercados. En efecto, el Reglamento tiene por objeto garantizar la salida al mercado de la producción comunitaria y de la producción tradicional ACP, lo que implica el establecimiento de un determinado equilibrio entre ambas categoría de operadores económicos afectados; En consecuencia, la imputación basada en la violación del principio de no discriminación debe desestimarse por infundada». STJUE de 5 de octubre de 1994, Alemania c. Consejo, C-280/93, Rec. 1994, p. I-4973, app., 74 y 74.

38 «A este respecto, procede subrayar que, en la sentencia Alemania c. Consejo [...] El Tribunal de Justicia consideró que dicho trato diferenciado no es contrario al principio general de no discriminación, en la medida en que es inherente al objetivo de una integración de mercados hasta entonces fragmentados [...] «, STJUE de 10 de marzo de 1998, T. 
Con relación a la segunda de las discriminaciones entiende el TJUE que: «una posible desigualdad de trato entre los productores de un Estado miembro y los de otros Estados miembros que, como en el presente caso, es mera consecuencia de las diferencias que existen entre las legislaciones de estos Estados miembros, no constituye una discriminación prohibida por el artículo 40, apartado 3, del Tratado, ya que la legislación nacional controvertida afecta a todos los productores interesados con arreglo a criterios objetivos $\rangle^{39}$.

En este segundo plano, que como queda constancia en la sentencia está consolidado en la doctrina del TJUE -en relación incluso con otros preceptos conectado con el principio de igualdad como el art. 7 del TCEE- ${ }^{40}$, nos encontramos también ante una horquilla de posibilidades bastante amplia. La misma nos remite a un problema jurídico complejo, que resulta tan apasionante en lo intelectual como negativo en el plano de la seguridad jurídica: los límites entre la constitucionalidad y la legalidad en el acervo de la Unión. Decir, como dice el TJUE, que no hay discriminación de iure cuando el trato desacorde responda a diversidad de normativas nacionales «es mera consecuencia de las diferencias que existen entre las legislaciones de estos Estados miembros», puede ser el final de los problemas planteados en relación al ámbito que aquí nos ocupa, pero también el comienzo de nuevos y espinosos.

Cuando la normativa nacional concurre, en el contexto estudiado, con el ámbito comunitario no es de extrañar que nos encontremos ante una normativa que directa o indirectamente traiga causa o guarde relación con una base jurídica habilitante del Derecho originario europeo. Así, el juego del Derecho de fuentes europeo demanda saber cuál es la dimensión constitucional de la normativa nacional y si estamos ante un problema de validez o de estricta aplicabilidad. Si estamos ante un problema de validez, se trata de ver

Port GmbH \& Co. c. Hauptzollamt Hamburg-Jonas, as. ac. C-364/95 y C-365/95, Rec. 1998 , p. I-1023, app. 82 у 83.

39 STJUE C-292/97, ap. 53.

40 «Las cuestiones tercera y cuarta del órgano jurisdiccional nacional pretenden saber si una normativa como la debatida contiene una discriminación incompatible con el artículo 7 del Tratado; El órgano jurisdiccional nacional planteó estas cuestiones por considerar que dicha normativa podría perjudicar a los exportadores sometidos a la misma en relación con los exportadores establecidos en otros Estados miembros y sujetos a un régimen diferente; Basta observar que una posible desigualdad de trato entre los exportadores establecidos en la UEBL [Unión Económica Belgo-Luxemburguesa] y sus competidores establecidos en otros Estados miembros es mera consecuencia de las diferencias que existen entre las legislaciones de los Estados miembros; según jurisprudencia reiterada de este Tribunal, dicha diferencia de trato no constituye una discriminación prohibida por el artículo 7 del Tratado, ya que la legislación controvertida afecta a todas las personas interesadas, con arreglo a criterios objetivos y sin relación con la nacionalidad», STJUE de 14 de julio de 1988, Lambert, 308/86, Rec. p. 4369, app. 19, 21 y 22. 
si una normativa nacional que impida un trato desigual contrario a los artículos 20 y 21 de la Carta puede ampararse en el hecho de que sea desarrollo de un ámbito competencia ajeno a la UE. Dicha lógica es la avalada por esta doctrina del TJUE y por el apartado segundo del artículo 51 de la Carta: «La presente Carta no amplía el ámbito de aplicación del Derecho de la Unión más allá de las competencias de la Unión, ni crea ninguna competencia o misión nuevas para la Unión, ni modifica las competencias y misiones definidas en los Tratados». Efectivamente, todo indica que se limita toda posibilidad de desarrollo de los artículos 20 y 21, e igualmente de la discriminación indirecta.

Hemos visto pues, como las sentencias citadas como paradigma de la recepción pretoriana del principio de igualdad en los altares de los principios fundamentales del Derecho europeo, distan de ser un reconocimiento ortodoxo en puridad constitucional. Las sentencias estudiadas al hilo de las tres sustantivas, lejos de mejorar el panorama introducen una pluralidad de excepciones que amenazan con hacer de la excepción la pauta. Sin perjuicio de que el desarrollo realizado ya posibilidad una conclusión, debemos referirnos a otro de los aspectos más característicos de la delimitación de trato dispar, a saber, el relacionado con el principio de solidaridad.

La sentencia de referencia en esta última parte de la exégesis, que no la única, es el asunto España c. Consejo, fallado en septiembre de $1988 .^{41}$ En él se traen a colación parámetros delimitadores del margen gozado por el legislador comunitario para dispensar un trato similar a situaciones disímiles, o lo que es igual: se delimita el concepto de «trato desigual objetivamente justificado».

En el presente caso, el Reino de España sostenía que la norma derivada contestada violaban el principio de no discriminación puesto que los mismos criterios se aplican indistintamente a todos los productores de leche de la Comunidad, cuando la situación particular del sector lácteo español exigía un trato diferenciado. A este respecto, el Reino de España destaca, en primer lugar que España es un país deficitario en productos lácteos; que no había participado en la producción de los excedentes comunitarios; que no se ha beneficiado de los mecanismos de sostenimiento de precios creados por la organización común de mercado de que se trataba en el caso y que, por otra parte, las estructuras productivas del sector lácteo español presentan un grado de eficiencia muy inferior al promedio comunitario.

El TJCE, pese a reconocer un grado destacable de veracidad en la disimilitud del supuesto de hecho expuesto, no consideró vulnerado el principio de no discriminación del artículo. Ello, como apuntó en su fundamento inicial

${ }^{41}$ STJUE de 20 de septiembre de 1988, España c. Consejo, C-203/86, Rec. 1988, p. 04563 
-que a continuación reproducimos- por la existencia de justificaciones objetivas: «Procede recordar ante todo que, según jurisprudencia constante de este Tribunal de Justicia, el principio de no discriminación entre productores o consumidores de la Comunidad consagrado en el párrafo 2 del apartado 3 del artículo 40, exige que no se trate de manera diferente situaciones comparables y que no se trate de manera idéntica situaciones diferentes, a no ser que dicho trato esté objetivamente justificado ${ }^{42}$.

Del principio general, sin sucesión de continuidad se deduce, «Por consiguiente, las medidas que conlleva la organización común de los mercados [...] no pueden ser diferenciadas, según las regiones y otras condiciones de producción o de consumo, más que en función de criterios objetivos que garanticen un reparto proporcional de las ventajas o desventajas entre los interesados, sin distinguir entre los territorios de los Estados miembros. $\gg{ }^{43}$ Es decir, lo objetivamente justificado se debe encontrar a través de la elaboración de un elenco de criterios, pero ¿cuáles son?. Ni en esta sentencia ni en otras encontraremos criterios generales que nos guíen. De hecho, la delimitación negativa que se aporta -que no puede depender de una distinción por razón del territorio de producción-, no es sino la natural aplicación del principio específico de no discriminación intracomunitaria. Tampoco, como pasamos a ver, se extraen dichos criterios del desarrollo de la desestimación.

Una parte del rechazo se fundamenta en el hecho de que la situación se encontraba cubierta por el Acta de adhesión: «el carácter diferente de este sector ha sido reconocido en el Acta de adhesión y que a dicho efecto se han previsto una serie de mecanismos de transición» ${ }^{44}$-en lo relativo a las estructuras de producción en el sector lácteo español-; o «que España aceptó, sin perjuicio de las disposiciones transitorias establecidas en el Acta de adhesión, la aplicación del acervo comunitario $\rangle^{45}$-en cuanto al hecho de que los agricultores españoles no se hayan beneficiado de los mecanismos de sostenimiento de precios-. Dicha lógica no parece responder a criterio objetivo alguno, en todo caso, respondería a la estricta aplicación de las fuentes del derecho. El Acta de Adhesión de un Estado en la UE, con independencia de ser un instrumento jurídico que nace de una relación bilateral, frente a la multilateral del las CIG, es parte conformadora del Derecho originario; de ahí que el legislador, de respetar los parámetros de aquél, mal puede violentar el principio. De hacerlo, nos encontraríamos ante una colisión entre la literalidad del Tratado y un principio surgido por la vía pretoriana. En conclusión, no había margen para el juego del criterio objetivo.

\footnotetext{
${ }^{42}$ Ibid., ap. 25.

43 Ibid.

${ }^{44}$ Ibid, ap. 27.

45 Ibid, ap. 28.
} 
Por ello, podría deducirse que el rechazo al último argumento se basaría, de forma nítida, en un criterio objetivo. Si recordamos, según el recurrente, el principio de no discriminación exige que no se aplique la reducción de la producción láctea a España debido a que este Estado era deficitario -hecho diferencial- en productos lácteos y a que no contribuyó a los excedentes comunitarios. El TJCE justificó dicha realidad con la necesidad de hacer un «esfuerzo de solidaridad» entre los Estados, por mor a alcanzar el objetivo comunitario, en este caso: la reducción de las cantidades globales garantizadas. Así, con independencia de que en este aspecto concreto hubiese antecedentes claros, ${ }^{46}$ ni en aquellos ni en esta sentencia, se encuentra un criterio extrapolable. Sobre la objetividad del mismo tampoco podemos ser generosos sobre todo por la parquedad de la fundamentación del TJCE que, en cualquier caso, no fundamenta por qué el «esfuerzo de solidaridad» no se distribuye, con el mecanismo más equitativo, entre todos los Estados, sobre todo entre los excedentarios.

Consecuentemente, bien puede afirmarse que el «esfuerzo de solidaridad» puede utilizarse como un cajón de sastre que retraiga el ámbito del principio de igualdad al antojo del legislador comunitario. Si hacemos un pequeño repaso a la doctrina, vemos que esta formulación no es un caso aislado. De hecho, la rationale de la sentencia recién estudiada se reproduciría en el asunto SITPA ${ }^{47}$. Igualmente, dicha formulación se ha mantenido con posterioridad al caso estudiado o, con cita literal al asunto previo, en el caso Crispoltoni: «[...] este Tribunal de Justicia ya ha declarado que el principio de no discriminación no se opone a una normativa comunitaria que haya establecido un sistema de umbrales de garantía para la totalidad del mercado comunitario que implique la reducción de la ayuda a la producción de los agentes económicos interesados de todos los Estados miembros, aunque la superación de dichos umbrales no sea consecuencia de un aumento de la producción en todos esos Estados. [...] todos los productores comunitarios, sea cual fuere el Estado miembro en que estén establecidos, deben asumir de

46 STJUE de 9 de julio de 1985, Bozzetti, 179/84, Rec. 1985, p. 2301.

47 «Dans la mesure où ce grief doit également être compris comme reprochant au Conseil et à la Commission d' avoir pénalisé les transformateurs français, alors que le dépassement de la production n' était pas dû à une augmentation de la production en France, il convient de souligner que, dans le cadre d' une organisation commune des marchés, ne connaissant pas un système de quotas nationaux, tous les producteurs communautaires doivent, quel que soit l' État membre dans lequel ils sont établis, assumer, de façon solidaire et égalitaire, les conséquences des décisions que les institutions communautaires sont appelées à prendre, dans le cadre de leurs compétences, pour réagir au risque d' un déséquilibre qui peut apparaître sur le marché entre la production et les possibilités d' écoulement», STJUE du 24 janvier 1991, Société industrielle de transformation de produits agricoles (SITPA), C-27/90, Rec. 1991, p. I-133. 
forma solidaria y por igual las consecuencias de las decisiones que tienen que tomar las Instituciones comunitarias, dentro del ámbito de sus competencias, a fin de reaccionar frente al riesgo de un desequilibrio que puede surgir en el

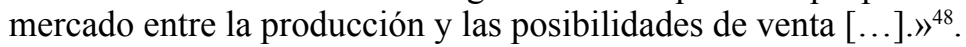

Es decir, en el caso Crispoltoni, nos encontramos ante una medida que hace tabla rasa frente a todos los productores con independencia de que solamente parte de ellos sean culpables - por la generación de excedente- de la medida a tomar. Se trata de un caso acentuado de situación de hecho diferenciada, ya que, no solamente presenciamos una situación objetiva es distinta, sino que la propia medida del legislador, que repercute negativamente en todos los sujetos pasivos potenciales de la norma, ha sido excitada por la actitud negligente de parte de ellos. La justificación del trato diferente, como no podía ampararse en el test del principio de igualdad -que demanda un trato diferente al sujeto pasivo disímil- se ampara en el principio de solidaridad. El mismo, como se observa, se sitúa en las antípodas de la objetividad de los parámetros que el principio de igualdad demanda para limitar el desapego del principio.

Por lo tanto, como puede observarse, de la jurisprudencia del TJUE no pueden extraerse un elenco de criterios que nos permitan determinar ni, por un lado, el test de comparación ni, por otro, el test de justificación objetiva. Por el contrario, se demuestra la facilidad de establecer excepciones a la aplicación del principio, permitiendo entender que las diferencias de trato están objetivamente justificadas, como la consecución del interés general perseguido por la Unión o la necesidad de la solidaridad entre Estados miembros.

\subsection{La jurisprudencia posterior a la aprobación de la CDF.}

Hasta el momento, hemos tenido ocasión de constatar el papel medular del TJUE en la génesis del principio objeto de estudio. También, en el apartado inmediatamente anterior, hemos definido el alcance de la doctrina el tribunal europeo en la materia y, a la sazón, hemos certificado que la CDF consolida la existencia del reconocimiento del principio genérico de igualdad en la doctrina del TJUE, atendiendo a la literalidad del precepto y de las explicaciones, tanto en la forma como en el fondo. Se trata ahora de ver si, tras la aprobación de la CDF, la jurisprudencia del TJUE sigue manteniendo su doctrina histórica sobre el principio general de igualdad o, si por el contrario, aprovecha la fortaleza de la «constitucionalización» del principio como una palanca para ampliar el alcance del mismo.

48 STJUE de 5 de octubre de 1994, Crispoltoni, as. ac. C-133/93, C-300/93 y C-362/93, Rec. 1994, p. I-4863, ap. 52. 
En el presente apartado se trata pues de verificar si la la CDF ha supuesto algún cambio en la jurisprudencia del TJUE, es decir, si ha permitido mejorar la garantía del principio analizado, o si por el contrario, no ha aportado un cambio significativo con respecto a la interpretación del principio llevada a cabo por el Tribunal. A este respecto, centraremos nuestro análisis en las cuestiones más problemáticas que ya se han adelantado en el apartado anterior: por un lado, el test de comparación que aplica el TJUE a la hora de abordar si las situaciones pueden entenderse comparables a efectos de determinar la vulneración o no del principio de igualdad; por otro, la delimitación de los criterios que acreditan que una diferencia de trato está objetivamente justificada. Examen que se realizará a partir de la jurisprudencia del TJUE adoptada a raíz de la aprobación de la Carta.

Como ya se ha reiterado, el principio de igualdad de trato requiere que situaciones comparables no sean objeto de un trato diferente, o que situaciones diferentes no sean tratadas de manera idéntica, salvo que la diferencia de trato esté objetivamente justificada. A efectos de determinar, por tanto, si dos situaciones pueden considerarse como comparables para, de ser así, pasar a verificar si la diferencia de trato se encuentra objetivamente justificada, el TJUE ha señalado que han de tenerse en cuenta el conjunto de elementos que caracterizan las situaciones comparables, elementos que deben apreciarse a la luz del objeto y la finalidad del acto europeo que establece la distinción de que se trata, así como de los principios y objetivos del ámbito al que pertenece el acto en cuestión. Por lo tanto, como ya hemos adelantado en el apartado anterior, el TJUE remite de esta manera al análisis del acto europeo y del ámbito al que pertenece, lo que demanda llevar a cabo un examen de los supuestos de hecho concretos de cada caso concreto. Análisis que implica, en último término, una gran dificultad para extraer unas pautas generales sobre la obtención de parámetros generales objetivos delimitadores del principio.

Como se examinará a continuación, la jurisprudencia del TJUE sigue siendo muy casuística, lo cual plantea además, como señala Bell, la problemática de que en última instancia se termina realizando siempre una valoración subjetiva por parte del juzgador, lo que puede llegar a terminar por perpetuar ciertas desigualdades ${ }^{49}$. Y, por lo que respecta a la delimitación

49 Así, el mencionado autor, para justificar dicha tesis, cita como ejemplo el asunto Österreichischer, asunto que trae causa de un litigio entre el Österreichischer Gewerkschaftsbund (sindicato de empleados del sector privado austriaco) y la Wirtschaftskammer Österreich (Cámara de Comercio de Austria), relativo a una reivindicación de igualdad de trato entre trabajadores de distinto genero respecto a la indemnización por despido. De acuerdo con la normativa austríaca, los períodos de prestación del servicio militar y del servicio civil sustitutorio se computaban como parte del período de empleo a efectos del cálculo de la cuantía de indemnización por despido, no incluyéndose como 
de lo que constituye una diferencia de trato objetivamente justificada, como ya se ha podido observar del análisis de la jurisprudencia anterior a la CDF, a la hora de procesar esta carga de objetivación (como es ortodoxo en la lógica de funcionamiento de los altos tribunales continentales) el tribunal europeo ha construido un test de justificación objetiva para examinar qué diferencias de trato son aceptables y cuáles no. Ahora bien, como ha apuntado la Abogada General Sharpston en el asunto Bartsch los criterios sobre qué similitudes y diferencias son pertinentes para la igualdad de trato varían según el punto de vista moral fundamental de una persona o de una sociedad

parte del mismo los períodos de excedencia voluntaria por cuidado de hijos. Al objeto de analizar si la diferencia de trato a la que da lugar la normativa nacional respeta el principio de igualdad (en este caso de retribución) examina si las mujeres y los hombres trabajadores se encuentran en una situación comparable. El resultado del examen lleva al tribunal a una conclusión negativa por los siguientes motivos. Por un lado, destaca el TJUE la diferencia entre el carácter voluntario y el carácter obligatorio de los distintos supuestos, señalando que mientras que la excedencia por cuidado de hijos es una excedencia a la que el trabajador se acoge de forma voluntaria, la prestación de un servicio nacional responde a una obligación cívica prevista por la ley y por motivos de interés público, no del propio trabajador. Por otro lado, añade que aunque el servicio nacional puede prolongarse voluntariamente, la misma no altera su naturaleza ya que sigue siendo satisfacer imperativamente una necesidad pública. Entiende, por tanto, que en cada caso el contrato se suspende por un motivo distinto (el interés del trabajador en el caso de la excedencia por cuidado de hijos y el interés nacional en el caso del servicio militar), por lo que los trabajadores afectados no se encuentran en una situación comparable. Concluyendo que de esta manera el art. $141 \mathrm{CE}$ y la Directiva 75/117 no se oponen a que en el cálculo de la indemnización por despido sólo se computen los períodos de prestación del servicio militar o del servicio civil sustitutorio y no los de excedencia por cuidado de hijos. STJUE de 8 de junio de 2004, Österreichischer Gewerkschaftsbund, Gewerkschaft der Privatangestellten c. Wirtschaftskammer Österreich, C-220/02, Rec. 2004 p. I-05907, app. 60-65. Así, el TJUE basa su conclusión exclusivamente en el análisis de la normativa nacional y en la aparente neutralidad de la misma, pues se excluyen los períodos de excedencia solicitados tanto por hombres como por mujeres. Sin embargo, no tiene en cuenta adecuadamente el hecho de que son mayoritariamente (por no decir unánimemente) las mujeres quienes solicitan las mismas; también sorprende que el tribunal considere indiscutido que la elección sea totalmente voluntaria, amparándose en la literalidad de la normativa reguladora e ignorando que de facto esa opción no es factible para la mujer en muchos casos. Vid. Bell, M., «Article 20», op. cit., p. 571. Como señala la Comisión, traer aspectos formales puede alejar la resolución de la justicia material. Así nos parece verlo cuando el ejecutivo comunitario señala que no es necesario comparar los dos regímenes de indemnización por despido involucrados en el asunto, pues ello no añade nada a la constatación de que la regulación restrictiva establecida por la normativa austríaca ya constituye por sí sola una discriminación y, además, no permite deducir ningún factor objetivo que pueda justificar dicha diferencia de trato de las mujeres. Österreichischer, app. 54-57. 
en concreto $^{50}$, y las respuestas a quién está amparado por el principio de igualdad de trato y qué aspectos de la vida económica, social, política, civil y personal abarca el mismo no son inmutables sino que evolucionan con la sociedad $^{51}$. Así, una diferencia entre un trato diferenciado aceptable y una discriminación inaceptable «no reside en si se trata a las personas de una manera diferencia, sino en si la sociedad acepta como justificables los criterios cuya aplicación resulta en un trato diferente o si, por el contrario, se consideran arbitrarios $\gg{ }^{52}$.

Así, un primer asunto en el que puede observarse cómo el TJUE mantiene la misma línea jurisprudencial examinada en el apartado anterior, previa a la CDF, es el asunto Arcelor Atlantique et Lorraine y otros, en el que se planteaba si la Directiva 2003/87/CE del Parlamento Europeo y del Consejo, por la que se establecía un régimen para el comercio de derechos de emisión de gases de efecto invernadero en la Comunidad, podía ser contraria al principio de igualdad ya que incluía en su ámbito de aplicación al sector siderúrgico, pero no al sector de los químicos y metales no férreos, al que pertenecen los sectores del plástico y el aluminio. El TJUE, a la hora de analizar si los citados sectores podía considerarse que se encontraban en una situación comparable, analiza el objeto de la Directiva (establecer un régimen comunitario para el comercio de derechos de emisión) y su finalidad (contribuir al cumplimiento de los compromisos adquiridos en virtud del Protocolo de Kioto), así como los principios y objetivos de la política de medio ambiente, ámbito al que pertenece la directiva en cuestión ${ }^{53}$. Análisis del que el Tribunal extrae la conclusión de que los sec-

${ }^{50}$ Conclusiones del Abogado General Sharpston presentadas el 22 de mayo de 2008, Birgit Bartsch contra Bosch und Siemens Hausgeräte (BSH) Altersfürsorge GmbH, C-427/06, Rec. 2008 p. I-07245, ap. 44.

${ }^{51}$ Ibid. ap. 46.

$52 \mathrm{Ibid}$. ap. 56. Aunque referido a la igualdad de trato entre trabajadores masculinos y femeninos, un asunto que ilustra la diferente percepción que una sociedad puede tener respecto a una problemática y cómo puede cambiar a lo largo del tiempo, es el asunto $P$ contra S y Cornwall County Council. En sus conclusiones, el Abogado General ilustra claramente cómo la cuestión de la transexualidad no era contemplada por la Directiva, pues era una realidad que en aquél momento sólo comenzaba a vislumbrarse (ap. 23), pero cómo en la actualidad debe darse una interpretación de la directiva en un sentido más amplio de manera que incluya todas las situaciones en las que el sexo sea un factor de discriminación, por lo que pedía al TJUE una decisión valiente ya que estaba en juego un principio fundamental universal como es el de la igualdad de trato con irrelevancia del sexo de la persona. Vid. Conclusiones del Abogado General Sr. Giuseppe Tesauro, presentadas el 14 de diciembre de 1995, en el asunto P contra S y Cornwall County Council, C-13/94, Rec. 1996 I-02143.

${ }^{53}$ Los mismos elementos son analizados en el asunto Sky Italia, en el que la posible diferencia de trato vulneradora del principio de igualdad que se planteaba era el establecimiento de límites horarios al tiempo de emisión de publicidad televisiva para los organismos 
tores mencionados se encuentran en una situación comparable en relación con el principio de igualdad de trato ${ }^{54}$, ya que toda emisión de gases de efecto invernadero puede contribuir a la producción de interferencias peligrosas en el sistema climático y cualquier sector de la economía que emita tales gases puede contribuir al funcionamiento del régimen de comercio de derechos de emisión ${ }^{55}$, si bien están recibiendo al tiempo un trato diferente. Trato diferente que, finalmente, concluye el tribunal que está objetivamente justificado.

A efectos de llegar a dicha conclusión, el TJUE vuelve a recordar que una diferencia de trato está justificada «cuando se basa en un criterio objetivo y razonable, es decir, cuando está en relación con un fin legalmente admisible perseguido por la legislación en cuestión, y esta diferencia es proporcionada al objetivo perseguido por dicho trato» ${ }^{56}$. De esta forma, tras examinar la justificación y datos aportados por el legislador europeo para acreditar la existencia de criterios objetivos para la diferencia de trato, señala que si bien ha reconocido al mismo, en el ejercicio de las competencias que se le confieren, una amplia facultad de apreciación cuando su acción implica tomar decisiones de naturaleza política, económica y social, y cuando debe realizar apreciaciones y evaluaciones complejas ${ }^{57}$, dicha facultad no obsta para que esté obligado a basar su elección en criterios objetivos y apropiados en relación con la finalidad perseguida por la legislación en cuestión, teniendo en cuenta todos los elementos de hecho, así como los datos técnicos y científicos disponibles en el momento de adoptar el acto de que se trate ${ }^{58}$. Así, teniendo en cuenta los datos aportados y la diferencia sustancial entre los niveles de emisiones directas de los distintos sectores, el TJUE señala que el trato diferente estaba justificado; añadiendo asimismo que el enfoque progresivo en que se

de radiodifusión televisiva de pago inferiores a los establecidos para los organismos de radiodifusión televisiva en abierto. El TJUE, analizando el objetivo de la Directiva de servicios de comunicación audiovisual (que por lo que respecta al tiempo de emisión de publicidad trata de lograr una protección equilibrada de los intereses económicos de los organismos de radiodifusión televisiva y de los anunciantes, por una parte, y de los intereses de los titulares de los derechos, a saber, los autores y los creadores, y de los consumidores que son los telespectadores, por otra parte), concluye que ambos operadores no se encuentran en una situación comparable, pues sus intereses económicos son diferentes, por lo que el TJUE entiende que no se había producido una vulneración del principio de igualdad por el establecimiento de dichos distintos límites. STJUE de 18 de junio de 2013, Sky Italia Srl. contra Autorità per le Garanzie nelle Comunicazioni, C-234/12, Rec. Electrónica, app. 15-23.

${ }^{54}$ STJUE de 16 de diciembre de 2008 Arcerlor Atlantique et Lorraine y otros, C-127/07, Rec. p. I-9895, ap. 38.

55 Ibid. ap. 34.

${ }^{56}$ Ibid. ap. 47.

57 Ibid. ap. 57.

${ }^{58}$ Ibid. ap. 58. 
basaba la normativa europea justificaba dicha diferencia ${ }^{59}$. Argumentos, todos estos, por los que concluía que no se había vulnerado el principio de igualdad de trato ${ }^{60}$.

Como puede observarse, el TJUE concede un amplio margen a la facultad de apreciación del legislador, limitándose a verificar si ha actuado basándose en criterios objetivos y no de forma arbitraria ${ }^{61}$. Aplica así un amplio margen para la justificación objetiva de la diferencia de trato.

Otro asunto en el que vuelve a observarse cómo se mantiene la jurisprudencia previa a la Carta, es el asunto Azienda Agricola Disarò Antonio y otros, en el que TJUE vuelve a recordar la necesidad del «esfuerzo de solidaridad» cuando se trata de alcanzar el objetivo de hacer frente al desequilibrio entre la oferta y la demanda de productos lácteos, en el cual deben participar por igual todos los productores de la Comunidad, y que el carácter deficitario de un Estado miembro carece de pertinencia a la hora de determinar la cantidad de referencia nacional, tal y como ya había señalado en el asunto España contra Consejo ya citado ${ }^{62}$. Por ello, señala el TJUE que las demandantes en el litigio principal no podían alegar que por el carácter defi-

${ }^{59}$ Ibid. app. 59-72

${ }^{60} \mathrm{Ibid}$. ap. 73. Idéntica conclusión a la que llega en el asunto Schaible, en la que el TJUE vuelve a recordar que una diferencia de trato está justificada cuando se basa en un criterio objetivo y razonable (ap. 77) y que corresponde al legislador de la Unión acreditar la existencia de criterios objetivos que justifiquen la diferencia de trato y aportar el Tribunal los datos necesarios para que pueda verificar la existencia de dichos criterios. Volviendo a hacer referencia a que en supuestos como el examinado, en que el legislador de la Unión ha de reestructurar o crear un sistema complejo, puede recurrir a un enfoque por etapas, siempre que el mismo se base en criterios objetivos y apropiados en relación con la finalidad perseguida por la legislación (ap. 91) Por ello concluye, que a la luz de las alegaciones expuestas por el legislador europeo, existían diferencias entre los distintos tipos de mamíferos (por una parte, el ganado ovino y caprino y, por otra, el ganado bovino y porcino) que justificaban un marco normativo propio para cada especie animal, estando justificada objetivamente la diferencia de trato y no produciéndose una vulneración del principio de igualdad de trato (app. 92-96). STJUE de 17 de octubre de 2013, Herbert Schaible contra Land Baden-Württemberg, C-101/12, Rec. Electrónica.

${ }^{61}$ Amplio margen de apreciación del legislador que se reconoce también en el asunto Agrargenossenschaft, en el que el TJUE señala que el control del juez debe limitarse a comprobar si la medida controvertida no adolece de error manifiesto o de desviación de poder, o si la autoridad de que se trate no ha sobrepasado claramente los límites de su facultad de apreciación. Vid. STJUE de 14 de marzo de 2013, Agrargenossenschaft Neuzelle eG contra Landrat des Landkreises Oder-Spree, C-545/11, Rec. Electrónica, ap. 43. Vid, asimismo, STJUE de 30 de junio de 2016, Lidl GmbH \& Co. KG c. Freistaat Sachsen, C-134/15, ap. 47.

62 STJUE de 14 de mayo de 2009, Azienda Agricola Disarò Antonio y otros c. Cooperativa Milka 2000 Soc. coop. arl., C-34/08, Rec. 2009 I-04023, app. 30-34. 
citario de la producción lechera italiana se encontraban en una situación diferente de la de los productores de leche en otros Estados miembros ${ }^{63}$. Destacando el tribunal que el hecho de que una medida adoptada en el marco de una organización común de mercados pueda tener repercusiones diferentes para determinados productores, en función de la naturaleza particular de su producción, no constituye una discriminación, ya que la medida se basa en criterios objetivos, adaptados a las necesidades del funcionamiento global de la organización común de mercado ${ }^{64}$. Se basa, por tanto, la justificación objetiva en las necesidades de funcionamiento de la organización común de mercado, pero no se especifica nada más. Es decir, sigue sin poder encontrarse en la sentencia un elenco de criterios que permitan abordar de forma más transparente el test de la justificación objetiva.

También sigue recordando el TJUE su jurisprudencia reiterada en la que enfatiza que los derechos fundamentales no constituyen prerrogativas absolutas, sino que pueden ser objeto de restricciones, siempre y cuando éstas respondan efectivamente a objetivos de interés general perseguidos por la medida en cuestión y no impliquen, habida cuenta del objetivo perseguido, una intervención desmesurada e intolerable que afecte al contenido esencial de los derechos así garantizados ${ }^{65}$. Señala el Abogado general Jääskinen, que el Tribunal busca así lograr un equilibrio entre los diferentes derechos e intereses, por un lado, y los derechos fundamentales y libertades económicas, por otro ${ }^{66}$. Vemos, por tanto, como la consecución de los objetivos de interés general perseguidos por la Unión y la protección de las libertades económicas, siguen jugando como elementos que pueden determinar el establecimiento de limitaciones a los derechos recogidos en la CDF, incluido entre ellos el de igualdad ${ }^{67}$.

$\mathrm{Y}$, asimismo, sigue manteniendo el Tribunal que las diferencias entre legislaciones nacionales no vulneran el principio de igualdad. Ello puede observarse en el asunto Schaible ${ }^{68}$, en el que el TJUE vuelve a recordar que la prohibición de discriminación no comprende las eventuales disparidades de trato que puedan derivarse, entre los Estados miembros, de las divergencias existentes entre las legislaciones de dichos Estados, siempre que tales

${ }^{63}$ Ibid. ap. 68.

${ }^{64}$ Ibid. ap. 69.

${ }^{65}$ STJUE de 18 de marzo de 2010, Alassini y otros, C-317/08 a C-320/08, Rec. p. I-2213, ap. 63.

${ }_{66}$ Opinión del Abogado General Sr. Niilo Jääskinen, presentada el 2 de mayo de 2014, en el asunto C-129/14 PPU, Zoran Spasic [petición de decisión prejudicial planteada por el Oberlandesgericht Nürnberg (Alemania)], ap. 83.

${ }^{67}$ SSTJUE de 15 de junio de 2006 Dokter y otros, C-28/05, ap. 75; de 2 de abril de 2009, Gambazzi, C-394/07, Rec. P. I-2563, ap. 29; y de 18 de marzo de 2010, Alassini y otros, C-317/08 a C-320/08, Rec. p. I-2213, ap. 63

${ }^{68}$ STJUE C-101/12, op. cit. 
legislaciones se apliquen a todas las personas sometidas a ellas ${ }^{69}$. A lo que, añade, debe tenerse en cuenta que la disparidad de estas legislaciones nacionales es compatible con el Derecho Europeo cando éste otorga un cierto margen de apreciación a los Estados miembros ${ }^{70}$.

De esta forma, el TJUE concluía que la excepción prevista en el Reglamento $21 / 2004$, por la que se autorizaba a los Estados miembros con una cabaña reducida de ovino o de caprino a decidir que el sistema de identificación electrónica fuese facultativo, no implicaba una discriminación entre los ganaderos de los Estados miembros en los que no se hubiese establecido dicho sistema y los demás ganaderos establecidos en la Unión, entendiendo que la citada excepción era de carácter objetivo y razonable ${ }^{71}$. Además, entendía el TJUE que dado que la excepción controvertida sólo autorizaba a los Estados miembros a decidir que la identificación electrónica individual fuese facultativa respecto de los animales que no fuesen objeto de intercambios intracomunitarios, un ganadero establecido en un Estado miembro en el que dicha identificación fuese obligatoria no sufría ninguna desventaja económica como consecuencia de los efectos comunes de la citada obligación y de la excepción controvertida ${ }^{72}$.

Por lo tanto, como puede observarse, la jurisprudencia del TJUE sigue siendo muy casuística, como ya se ha destacado en los asuntos examinados en el apartado anterior y que se citan en las explicaciones anejas a la CDF, en las aclaraciones de la Carta, como plasmación de la doctrina del Tribunal de Justicia, que lo considera un principio fundamental del Derecho de la Unión como se ha señalado. Hecho que, como ya se ha adelantado, dificulta extraer unas pautas generales sobre la obtención de parámetros generales objetivos delimitadores del principio. Y seguimos encontrando en la jurisprudencia del TJUE numerosos supuestos en los que la excepción al principio de igualdad se convierte en la regla: la consecución de los objetivos de interés general de la Unión, la facultad de apreciación de la que goza el legislador europeo, la solidaridad entre Estados miembros o la disparidad de legislaciones nacionales son elementos destacados de forma constante en la jurisprudencia del TJUE como criterios que justifican de forma objetiva la diferencia de trato. Ámbitos, todos ellos, en los que el TJUE aplica un amplio margen para la justificación de la diferencia de trato. Por tanto, la línea argumental principal de las sentencias citadas en las Explicaciones a la Carta se mantiene en la jurisprudencia posterior a la entrada en vigor de la misma.

\footnotetext{
${ }^{69}$ Ibid., ap. 87.

70 Ibid.

${ }^{71}$ Ibid., app. 80-85.

${ }^{72}$ Ibid., ap. 86.
} 
Por el contrario, si pueden encontrarse unos criterios más detallados en la jurisprudencia del TJUE relativa al principio de igualdad de trato y no discriminación entre trabajadores ${ }^{73}$. Ahora bien, ha de tenerse en cuenta que se trata de un ámbito en el que la Unión Europea cuenta con una abundante normativa $^{74}$, así como que el hecho de que el énfasis en el concepto de igualdad formal empleado por la jurisprudencia del TJUE haya determinado que se haya desarrollado más la igualdad desde su dimensión negativa, es decir, desde el principio de no discriminación, como señala $\mathrm{O}^{\prime}$ Cinneide $^{75}$.

Así, por lo que respecta al test de comparación, para apreciar si dos tipos de trabajadores se encuentran en una situación comparable el TJUE ha señalado que pueden tenerse en cuenta un conjunto de factores como la naturaleza del trabajo, los requisitos de formación y las condiciones laborales. Estos pueden observarse, por ejemplo, en el asunto De Diego Porras, en el que se planteaba si era contraria al principio de discriminación una normativa que no reconoce derecho de indemnización a los trabajadores interinos pero si a los trabajadores con contrato de duración determinada. El TJUE señalaba que ambos tipos de trabajadores se encontraban en una situación comparable, al observar que la recurrente cumplía no solo los requisitos de formación para acceder al puesto de trabajo, sino que también efectuaba el mismo trabajo que la persona a la que había reemplazado ${ }^{76}$. Ahora bien, debe tenerse en cuenta que, como se ha señalado, en este ámbito la Unión cuenta con una amplia normativa cuyo objetivo es eliminar las desigualdades de trato entre trabajadores, de la que el TJUE extrae los criterios que pueden aplicarse a efectos de realizar el test de comparación; y que, por otra parte, sigue tratándose de una jurisprudencia casuística en la que en todo caso el tribunal debe examinar los hechos del caso concreto.

Y, por lo que respecta al test de justificación objetiva, el TJUE utiliza también un rasero sensiblemente distinto al que se ha examinado en las sentencias anteriores, determinando de forma más precisa los criterios que pueden tomarse en cuenta para analizar si la diferencia de trato está objetivamente justificada. Así, el TJUE ha señalado que el concepto de «razones objetivas» requiere que la desigualdad de trato esté justificada por la existencia de elementos precisos y concretos, que caracterizan la condición de trabajo de que se trata, en el contexto específico en que se enmarca y con arreglo a criterios

${ }^{73}$ Un análisis de jurisprudencia reciente en relación a la Directiva de igualdad en materia de empleo puede consultarse en S. Peers, «The EU Charter of rights and the right to equality», ERA Forum 02/2011, Vol. 11/4.

74 Vid. M. Bell, «Article 20», op. cit., 575.

75 Vid. C. O'Cinneide, op. cit.

76 STJUE de 14 de septiembre de 2016, Ana de Diego Porras contra Ministerio de Defensa, C-596/14, app. 40-44. 
objetivos y transparentes. Todo ello, con el objeto de verificar si la desigualdad responde a una necesidad auténtica, si permite alcanzar el objetivo perseguido y si resulta indispensable al efecto. En esta lógica el tribunal considera que dichos elementos pueden tener su origen en la especial naturaleza de las tareas para cuya realización se celebran los contratos de duración determinada y en las características inherentes a las mismas, o en la persecución de un objetivo legítimo de política social por parte de un Estado miembro $^{77}$, añadiendo que el hecho de que una norma nacional general y abstracta, como una ley o convenio colectivo, prevea la diferencia de trato no permite justificar de forma objetiva la misma ${ }^{78}$.

En coherencia interpretativa con lo dicho, el TJUE ha extendido el principio de igualdad de trato a los trabajadores a tiempo parcial o con contrato de duración determinada. En Del Cerro Alonso, el TJUE señala que la normativa europea se opone al establecimiento de una diferencia de trato entre trabajadores con un contrato de duración determinado y trabajadores fijos por lo que se refiere al complemento económico por antigüedad, justificada por la mera circunstancia de que esté prevista por una disposición legal o reglamentaria de

77 Vid. SSTJUE de 13 de septiembre de 2007, Yolanda Del Cerro Alonso contra Osakidetza-Servicio Vasco de Salud, C-307/05, Rec. 2007 I-07109, app. 53 y 58; de 22 de diciembre de 2010, Rosa María Gavieiro Gavieiro (C-444/09) y Ana María Iglesias Torres (C-456/09) contra Consellería de Educación e Ordenación Universitaria de la Xunta de Galicia, C-444/09 y C-456/09, Rec. 2010 I-14031, ap. 55; de 8 de septiembre de 2011, Francisco Javier Rosado Santana contra Consejería de Justicia y Administración Pública de la Junta de Andalucía, C-177/10, Rec. 2011 I-07907, ap. 73; de 14 de septiembre de 2016, Ana de Diego Porras contra Ministerio de Defensa, C-596/14, ap. 45; y de 21 de septiembre de 2016, Carlos Álvarez Santirso contra Consejería de Educación, Cultura y Deporte del Principado de Asturias, C-631/15, ap. 51. Ha de destacarse como, a nivel interno, los jueces y tribunales nacionales reciben esta jurisprudencia del TJUE. En el caso de España, no obstante, como señala Miryam Rodríguez, el Tribunal Constitucional mantiene una «doble visión de la relación con el derecho de la UE en materia de derechos fundamentales, una para él y otra para la jurisdicción ordinaria», doble visión, señala, que implica que se produzca una bifurcación por lo que respecta a la jurisprudencia de referencia sobre la dimensión sustantiva de ciertos derechos. Así, cita como ejemplo la Sentencia del Tribunal Constitucional 235/15, en la que pese a admitir el Alto Tribunal el recurso de amparo ya que le podría permitir valorar si mantener o matizar su doctrina con respecto a la proyección del derecho a la igualdad entre los funcionarios de carrera y los funcionarios interinos, finalmente no llevó a cabo tal valoración por cuestiones derivadas de la lógica hermenéutica propia de su función y mantuvo la jurisprudencia establecida desde la sentencia 7/1984. Vid. M. Rodríguez-Izquierdo Serrano, «Pluralidad de jurisdicciones y tutela de derechos: los efectos de la integración europea sobre la relación entre el juez ordinario y el tribunal constitucional», Revista Española de Derecho Constitucional, 107 (mayo-agosto 2016), 137.

78 Vid. Del Cerro Alonso, ap. 57; Gavieiro Gavieiro e Iglesias Torres, ap. 54; Rosado Santana, ap. 72; De Diego Porras, ap. 46; y Álvarez Santirso, app. 48 y 56. 
un Estado miembro o por un convenio colectivo celebrado entre la representación sindical del personal y el empleador, ya que una disposición nacional que se limita a autorizar la utilización sucesiva de contratos de trabajo de duración determinada de un modo general y abstracto a través de las citadas normas no constituye una razón objetiva que justifique la diferencia de trato ${ }^{79}$.

No se hace referencia en el citado asunto al art. 20 de la Carta, tampoco al principio de igualdad (se hace referencia al principio de no discriminación, utilizando la misma definición adoptada para el principio de igualdad $)^{80}$, pero ha de tenerse en cuenta que el TJUE ha reconocido que la prohibición de discriminación es una expresión específica del principio general de igualdad ${ }^{81}, \mathrm{y}$ que también ha señalado que el principio de igualdad actualmente se encuentra consagrado por los artículos 20 y 21 de la Carta. Es claro, que en el asunto se plantea un problema de igualdad de trato entre distintas clases de trabajadores, por lo que quizás habría sido conveniente que el TJUE hiciese referencia al artículo 20 de la Carta. Se observa, por tanto, como en los ámbitos en los que la UE cuenta con normativa detallada el TJUE aborda la delimitación de la justificación de las diferencias de trato desde la aplicación de dicha normativa, sin hacer mención a la Carta. Cuando, en otros supuestos, ha demostrado que no habría ningún inconveniente para ello, como en el asunto Zoi Chatzi ${ }^{82}$.

Luego, siguen manteniéndose numerosas excepciones al principio de igualdad (la consecución de los objetivos de interés general de la Unión, la facultad de apreciación de la que goza el legislador europeo, la consecución

${ }^{79}$ Del Cerro Alonso, op. cit., app. 49-59. Otro asunto contemporáneo a destacar en este contexto sería el asunto De Diego Porras. En este caso, la normativa española denegaba cualquier indemnización por finalización de contrato a los trabajadores al servicio de la Administración Pública con contrato de interinidad, mientras, a la sazón, sí reconocía tal indemnización a los trabajadores con contrato de duración determinada comparables. El TJUE señala que el recurso a la mera naturaleza temporal de la relación no es conforme a los requisitos señalados y no puede constituir una razón objetiva para la diferencia de trato, como tampoco el hecho de que la normativa nacional no prevea la concesión de indemnización por finalización de un contrato de trabajo de interinidad. Añadiendo que admitir que la mera naturaleza temporal de la relación basta para justificar la diferencia de trato privaría de contenido a la normativa europea y perpetuaría el mantenimiento de una situación desfavorable para estos trabajadores. De Diego Porras, op. cit., app. 47 y 50.

${ }^{80}$ Ibid. ap. 35.

${ }^{81}$ STJUE de 12 de octubre de 2004, Nicole Wippel c. Peek \& Cloppenburg GmbH \& Co KG, C-131/02, Rec. 2004 I-09483, ap. 56. Vid. Bell, op. cit., p. 575.

82 Asunto relativo a la concesión del permiso parental por el nacimiento de gemelos y la interpretación del Acuerdo marco sobre el permiso parental, celebrado el 14 de diciembre de 1995 que figura en el anexo de la Directiva 96/34/CE del Consejo, de 3 de junio de 1996. STJUE de 16 de septiembre de 2010, Zoi Chatzi contra Ypourgos Oikonomikon, C-149/10, Rec. 2010 I-08489, ap. 63. 
del mercado interior, la solidaridad entre Estados miembros, la disparidad de legislaciones nacionales), mediante los cuales el TJUE justifica de forma objetiva la diferencia de trato.

La CDF es un punto de llegada no un punto de partida, es la consolidación de lo que el TJUE entiende no solamente como una recepción adecuada de su doctrina sino, una constatación de que para el tribunal el principio ya había alcanzado su techo en el Derecho Comunitario sin necesidad de la CDF.

Donde si puede observarse que el TJUE realiza un control más riguroso del test de justificación, es allí donde ha de aplicarse la normativa en materia de igualdad de trato y no discriminación entre trabajadores, donde pueden encontrarse criterios más rigurosos sobre cómo realizar el test de comparación así como para la determinación de la justificación objetiva de las diferencias de trato ${ }^{83}$. Sin embargo, dicho desarrollo se mantiene en un plano formal y no tiene ningún efecto reseñable en alterar el núcleo y alcance del principio.

Por lo tanto, el estudio cronológico de la jurisprudencia del TJUE tras la aprobación de la CDF, constata que el TJUE sigue manteniendo que el principio general de igualdad es un principio general del Derecho de la Unión y que requiere, por un lado, que no se traten de manera diferente situaciones comparables y, por otro, que situaciones diferentes no sean tratadas de manera idéntica, salvo que dicho trato diferente esté justificado objetivamente, enfatizándose que el principio examinado se encuentra consagrado por los artículos 20 y 21 de la Carta $^{84}$, pero manteniéndose las principales excepciones al principio ya apuntadas por la jurisprudencia previa a la Carta.

\section{CONCLUSIÓN.}

El reconocimiento del principio de igualdad ante la ley en el derecho comunitario fue creado en su esencia por el TJUE: basándose esencialmente en los reconocimientos sectoriales del Derecho Originario y en los reconocimientos establecidos en los ordenamientos de los EEMM, estos últimos en dialéctica con sus tribunales constitucionales ${ }^{85}$. La CDF cristalizó esa creación en el fondo -recogiendo su esencia- y en la forma - explicitando en el

${ }^{83}$ A este respecto, vid. M. Bell, «Article 20», op. cit., 571 y ss.

${ }^{84}$ Vid., por ejemplo, SSTJUE de 22 de mayo de 2014, Wolfgang Glatzel contra Freistaat Bayern, C-356/12, Rec. Jurisprudencia electrónica, ap. 43; de 21 de julio de 2011, Károly Nagy contra Mezőgazdasági és Vidékfejlesztési Hivatal, C-21/10, Rec. 2011 p. I-06769, ap. 47; y de 14 de septiembre de 2010, Akzo Nobel Chemicals Ltd v. Comisión, C-550/07 P, Rec. 2010 p. I-08301, ap. 54.

${ }^{85}$ Al respecto, vid. J. M. Martínez Sierra, «La Recepción del Derecho Comunitario...», op. cit. 
Título VII de la carta los límites que el TJUE venía aplicando al principio de igualdad-, consagrado lo que podríamos denominar una «igualdad para un mercado».

Como hemos demostrado con la comparación de la jurisprudencia del TJUE, la aprobación de la CDF no produce ningún salto cualitativo en el reconocimiento de la igualdad ante la Ley en el Derecho Comunitario. Si de muestra vale un botón, conviene recordar que el propio TJUE ya mencionó la $\mathrm{CDF}$ antes de su entrada en vigor. Así, las enseñanzas que extraemos de la doctrina estudiada $-y$ que se mantiene en muchas otras ${ }^{86}$ - son claras, la configuración del principio permite potencialmente confundir la excepción con el principio: desde el interés general, a la búsqueda de la superación del fraccionamiento del mercado, pasando por la solidaridad entre los EEMM y la disparidad de legislaciones nacionales, el legislador europeo encuentra un amplísimo margen para sortear el principio de igualdad. Dichas palabras se han venido refrendando en la práctica jurisprudencial comunitaria. De todos los asuntos históricos estudiados, solamente el asunto Port terminó con un reconocimiento explícito de la vulneración del principio estudiado, pese a que en la inmensa mayoría el TJUE reconoció la existencia de un trato desigual de hecho.

En relación con el párrafo anterior y dimensionando esa conclusión, hemos de recordar que las sentencias citadas por la Convención como paradigma de la recepción pretoriana del principio de igualdad en los altares de los principios fundamentales del Derecho europeo, distan de ser un reconocimiento ortodoxo en puridad constitucional. Las sentencias estudiadas al hilo de las tres sustantivas, lejos de mejorar el panorama introducen una pluralidad de excepciones que amenazan con hacer de la excepción la regla. Sin prejuicio del desarrollo posterior en estas conclusiones, podemos ya concluir que cualquier estudio omnicomprensivo de la cuestión debe referirse a otro de los aspectos más característicos de la delimitación de trato dispar, a saber, el relacionado con el principio de solidaridad.

Los mayores impactos encontrados en la doctrina del TJUE tras la entrada en vigor de la $\mathrm{CDF}$ es la reciente jurisprudencia sobre igualdad de trato cuando aborda asuntos en materia de protección de los trabajadores, específicamente en sentencias sobre los trabajadores a tiempo parcial o con

${ }^{86}$ Véanse por ejemplo las SSTJCE de 19 de octubre de 1977, Ruckdeschel y Ströh, as. ac. 117/76 y 16/77, Rec. p. 1753, ap. 7; Moulins et Huileries de Pont-à-Mousson y Providence agricole de la Champagne, as. ac. 124/76 y 20/77, Rec. p. 1795, ap. 16; de 25 de octubre de 1978, Koninklijke Scholten-Honig y De Bijenkorf, 125/77, Rec. p. 1991, ap. 26, y Royal Scholten-Honig y Tunnel Refineries, as. ac. 103/77 y 145/77, Rec. p. 2037, ap. 26; de 10 de enero de 1992, Kühn, C-177/90, Rec. 1992, p. I-64, ap. 18; de 27 de enero de 1994, Herbrink, C-98/91, Rec. 1994, p. I-257, ap. 27. 
contrato de duración determinada. Dicha doctrina, no altera la conclusión anterior-la CDF no produce ningún salto cualitativo en el reconocimiento de la igualdad ante la Ley en el Derecho Comunitario-, pues lejos de enmarcarse en una doctrina vanguardista novedosa que se apoya en el contenido de la $\mathrm{CDF}$, se trata de un reconocimiento que encaja perfectamente en la «igualdad para un mercado» dado que dichas discriminaciones, de permitirse -en unos EEMM o sectores económicos frente a otros-distorsionarían el funcionamiento efectivo de las libertades básicas.

En la conclusión anterior se encuentra implícita la siguiente, a saber: el «constituyente» de la carta no se empapó del momento histórico ni de las vanguardias en el ámbito de la igualdad, ello lo indica tanto la literalidad del precepto como la doctrina del TJUE estudiada. No encontramos indicios suficientes para sentenciar la superación de la simple igualdad de trato $a b$ inito, ni en relación con la persecución de la igualdad de resultados ni en la concepción de la igualdad como diversidad. Aún así la variedad de las justificaciones desplegadas en la CDF permite afirmar que el constituyente faculta al legislador para utilizar los tres tipos de política legislativa estudiados en la introducción o una combinación de ellos: a través del principio de no discriminación, buscando la igualdad sustantiva y/o buscando la armonía entre igualdad y diversidad. Así lo dicho sobre la doctrina del TJUE debe de entenderse como un suelo de reconocimiento constitucional

La regulación del la Carta dentro del Derecho Originario, particularmente debido a las limitaciones del Título VII de la misma, imposibilitarán el desarrollo pleno del principio de igualdad a manos del TJUE. Por ello, en ningún caso alcanzará la centralidad y alcance que ocupa en la mayoría de los ordenamientos de los Estados miembros. Por ello, promete seguir sin grandes cambios la configuración que del mismo ha realizado desde siempre el TJUE por la vía pretoriana. Esta configuración convierte la doctrina del TJUE en esencial de cara al futuro y garantiza que el único salto cualitativo vendrá de la mano del desarrollo que del principio estudiado pudiera realizar la «Ley comunitaria». 